\title{
Rutin has anti-asthmatic effects in an ovalbumin-induced asthmatic mouse model
}

\author{
Hong-yan Lv' ${ }^{1}$, Jing Chen ${ }^{2}$ and Ting Wang ${ }^{3 *}$ \\ ${ }^{1}$ Department of Pediatrics, Shandong Jining No.1 People's Hospital, Shandong 272000, ${ }^{2}$ Department of Pediatrics, Affiliated \\ Hospital of Jining Medical University, Xiamen 361000, ${ }^{3}$ Out-patient Department, Affiliated Hospital of Jining Medical College, \\ Jining 272000, China
}

*For correspondence: Email: Ihy_angel@163.com; Tel/Fax: 0086-0537-3616166

\begin{abstract}
Purpose: To investigate the anti-asthmatic effects of the flavonoid rutin in an ovalbumin (OVA)-induced asthmatic mouse model.

Methods: Asthma was induced by OVA induction. Effects of rutin (25-100 mg/kg BW) on interleukins (IL)-4, IL-5, and IL-13 and interferon (IFN)-y in bronchoalveolar lavage fluid (BALF) and serum OVAspecific IgE levels were assessed by enzyme linked immunosorbent assay (ELISA). Airway hyperresponsiveness (AHR) was measured by determining lung compliance and airway resistance. Expression levels of $p-I-K B a, p-N F-K B$ p65, TNF-a, and Foxp3 were also assessed. The $C D 4^{+} C D 25^{+}$ Foxp $3^{+} T$ regulatory cell population was determined by flow cytometry.

Results: Rutin significantly $(p<0.05)$ decreased Th2 cytokines $(I L-4, I L-5, I L-13)$, whereas it enhanced IFN-y levels in BALF. Decreased OVA-specific serum IgE was also observed with improved lung histology. Rutin was effective in reducing AHR and regulating the expression levels of $p-I-k B a, p-N F-k B$ p65, and TNF $\alpha$, and also increased the $C D 4^{+} C D 25^{+}$Foxp3 ${ }^{+}$Treg cell population and Foxp3 mRNA and protein levels.

Conclusion: Rutin effectively suppresses OVA-induced asthma and improves airway function by suppressing inflammatory mediators and inflammatory cell infiltration.
\end{abstract}

Keywords: Asthma, $C D 4^{+} \mathrm{CD}^{+} 5^{+}$, Cytokines, Inflammation, Ovalbumin, Rutin, Protein levels

Tropical Journal of Pharmaceutical Research is indexed by Science Citation Index (SciSearch), Scopus, International Pharmaceutical Abstract, Chemical Abstracts, Embase, Index Copernicus, EBSCO, African Index Medicus, JournalSeek, Journal Citation Reports/Science Edition, Directory of Open Access Journals (DOAJ), African Journal Online, Bioline International, Open-J-Gate and Pharmacy Abstracts

\section{INTRODUCTION}

Allergic asthma is a chronic airway disorder characterised by airway inflammation, airway hyperresponsiveness (AHR), and mucus hypersecretion [1]. The prevalence of asthma is increasing globally, especially in children [2]. An imbalance in the equilibrium between $T$ helper cell type 1 (Th1) and T helper type 2 (Th2) immune responses appears to be the underlying mechanism that leads to the asthmatic inflammatory response, with an increased Th2 response [3]. Th2 cell-derived cytokines (IL-4, IL5 , IL-13) play key roles in the pathogenesis of asthma and have been implicated in AHR development, eosinophil accumulation, mucus hypersecretion, and lung remodelling [4].

It has also been demonstrated that NF-KB plays an important role in the pathogenesis of asthma [5]. NF-KB has been shown to be involved in the production of Th2 cytokines and in the recruitment of inflammatory cells [6], making NF$\mathrm{KB}$ a potential molecular target in therapeutic strategies for asthma. Corticosteroids have long been used as the main therapeutic drug in asthma [7]. However, such treatments do not 'cure' the disease or even alter disease 
progression; indeed, the symptoms return soon after treatment termination and the prolonged use of corticosteroids causes systemic and local side effects [8].

The use of natural plant products as alternative medicines in the treatment of various disease conditions has increased [9]. The flavonoids are a family of common phenolic plant pigments that possess anti-carcinogenic and anti-oxidant properties. Studies have also shown profound immunoregulatory activities [10]. Rutin, a flavonoid found especially in citrus fruits, such as lemon, grapefruit, lime, and orange, has antioxidant and anti-inflammatory activities [11]. Here, we investigated whether rutin could offer protection in asthmatic mice, via downregulation of inflammatory mediators, and improve airway function.

\section{EXPERIMENTAL}

\section{Chemicals and antibodies}

Antibodies against p-NF-kB p65, p-lк-Ba, TNF-a, Foxp3, and $\beta$-actin were from Cell Signaling Technology (Beverly, MA, USA). Rutin and ovalbumin (OVA) were from Sigma-Aldrich (St. Louis MO, USA). FITC-labelled anti-rat CD4, APC-labelled anti-rat CD25, and PE-labelled anti-rat Foxp3 were from eBioscience Co. (San Diego, CA, USA). All other chemicals and reagents used were from Sigma-Aldrich unless stated otherwise.

\section{Experimental animals}

Female BALB/c mice (18-22 g) were obtained from the Experimental Animal Centre of China Pharmaceutical University (Nanjing, China). All animals were housed in a sterile room (24 \pm 1 ${ }^{\circ} \mathrm{C}, 40-60 \%$ humidity) and were supplied with water and food ad libitum. The mice were acclimatised to the conditions for 1 week prior to experimentation. All experiments were performed in compliance with the Guidelines For the Care and Use of Laboratory Animals [12] and the study was approved by the Ethics Committee of Jining Medical University (Approval reference number:YXSA12443).

\section{Ovalbumin sensitisation and challenge}

Mice were sensitised and challenged with OVA as described previously [13] with minor modifications. OVA at $500 \mu \mathrm{g} / \mathrm{mL}$ in PBS was mixed with equal volumes of $10 \%(\mathrm{w} / \mathrm{v})$ aqueous aluminium potassium sulphate (alum; Sigma) and incubated at room temperature for about $1 \mathrm{~h}$ at $\mathrm{pH} 6.5$ and centrifuged $(750 \mathrm{~g}, 5 \mathrm{~min})$. The
OVA/alum pellet was suspended to its original volume in distilled water. The animals were given $100 \mu \mathrm{g}$ of OVA $(0.2 \mathrm{~mL}$ of $500 \mu \mathrm{g} / \mathrm{mL}$ solution in normal saline) intraperitoneally (i.p.) on the first day. Mice were exposed to $250 \mu \mathrm{g}$ OVA $(100 \mu \mathrm{L}$ of a $2.5 \mathrm{mg} / \mathrm{mL}$ solution) on day 8 , and on days 15,18 , and 21, mice were challenged with 125 $\mu \mathrm{g}$ OVA $(50 \mu \mathrm{L}$ of $2.5 \mu \mathrm{mg} / \mathrm{mL}$ solution) intranasally (i.n.), as described previously [13]. Mice were exposed to ketamine anaesthesia (i.p. injection of $0.2 \mathrm{~mL}$ of a mixture of ketamine, 0.44 $\mathrm{mg} / \mathrm{mL}$, and xylazine, $6.3 \mathrm{mg} / \mathrm{mL}$, in normal saline) prior to OVA challenge. In the treatment group, rutin was administered at 25, 50, $100 \mathrm{mg} / \mathrm{kg}$ bodyweight (BW) orally every day from day 1 to day 21 . On the days of OVA challenge, the mice received rutin $60 \mathrm{~min}$ before injections. A separate group of mice received dexamethasone (Dex; $2 \mathrm{mg} / \mathrm{kg}$ ) i.p. $1 \mathrm{~h}$ before OVA injections. Dex served as a positive control. The normal control mice received no injections or rutin.

\section{Collection and analysis of bronchoalveolar lavage fluid (BALF)}

The mice were sacrificed after $24 \mathrm{~h}$ following the last OVA challenge, by pentobarbital overdose, and a tracheotomy was performed. Ice-cold PBS $(0.5 \mathrm{~mL})$ was infused into a lung and BALF was obtained by three successive aspirations (total volume $1.5 \mathrm{~mL}$ ) via tracheal cannulation [14]. The collected BALF was then centrifuged (250 g, $5 \mathrm{~min}, 4^{\circ} \mathrm{C}$ ) and the supernatant was collected and stored at $-70^{\circ} \mathrm{C}$. The supernatant was used for cytokine assays. The cell pellets were resuspended in PBS and differential cell counts were determined by staining with the WrightGiemsa staining method.

BALF levels of IL-4, IL-5, IL-13 and IFN-y were determined using ELISA. Kits were purchased from R\&D Systems (Minneapolis, MN, USA).

\section{Determination of OVA-specific $\lg E$}

Whole blood was collected and centrifuged (3, $000 \mathrm{rpm}, 10 \mathrm{~min}, 4^{\circ} \mathrm{C}$ ) and the serum was separated and stored at $-80{ }^{\circ} \mathrm{C}$. OVA-specific serum $\lg E$ levels were determined using the Legend Max mouse OVA-specific IgE ELISA kit (BioLegend, San Diego, CA, USA) according to the manufacturer's protocol.

\section{Measurement of airway hyperresponsiveness}

Change in airway function was assessed as AHR, following challenge with aerosolised methacholine via the airway. AHR was determined using Buxco's modular and invasive 
system (Buxco Electronics Inc., Wilmington, NC, USA). Changes in lung compliance (Cdyn) and airway resistance $(\mathrm{Rl})$ in response to increasing concentrations of methacholine were recorded directly, as described previously [15]. Briefly, the rats were tracheotomised and cannulated and placed in a whole body plethysmograph chamber connected to the ventilator. The rats were given various concentrations of methacholine (3.125, $6.25,12.5,25 \mathrm{mg} / \mathrm{mL}$ ) via a jet nebuliser into the head chamber. The values are expressed as percentage of the respective basal values in response to phosphate-buffered saline (PBS).

\section{Histological analysis}

Lung tissues were collected and fixed in $10 \%$ formalin, and embedded in paraffin wax; $5-\mu \mathrm{m}$ sections were cut and stained with haematoxylin and eosin (H\&E). For examination of mucus production, periodic acid-fluorescence Schiff stain (PAFS) was used. The mucin granules emit red fluorescence at excitation wavelengths of $380-580 \mathrm{~nm}$ and were observed at $600-650 \mathrm{~nm}$ using a Leica TCS SP5 confocal microscope (Leica Microsystems, Richmond, IL, USA) as described previously [16]. The inflammatory scores and expression levels of mucus-positive cells were calculated as described previously [17].

\section{Flow cytometric analysis for $\mathrm{CD}^{+} \mathrm{CD}^{+} 5^{+}$ Foxp $^{+}$expression}

Cells from the BALF were analysed for $\mathrm{CD}^{+}$ $\mathrm{CD}^{2} 5^{+} \mathrm{Foxp}^{+}$expression. Briefly, prepared cells $\left(1 \times 10^{6}\right)$ were washed by centrifugation in flow cytometry staining buffer. For Treg analysis, cells were incubated with FITC-labelled anti-CD4 and APC-labelled anti-CD25 antibodies in staining buffer and incubated for $30 \mathrm{~min}$ at $4{ }^{\circ} \mathrm{C}$. Following surface staining, the cells were fixed, permeabilised, and subsequently stained with anti-rat Foxp3 and finally resuspended in staining buffer and subjected to analysis by flow cytometry (FACSCalibur instrument with CellQuest software; BD Biosciences, Mountain View, CA, USA).

\section{Quantitative real-time (RT)-PCR}

The lung tissues of each group were homogenised in $1 \mathrm{~mL}$ of TRIzol (Invitrogen) using a glass homogeniser. Total RNA was isolated according to the manufacturer's protocol. RNA specific for Foxp3 was amplified using specific primers: Foxp3, 5'-CCC TCA AAG TTA CAA TCCTG-3' (forward) and 5'-GGG TTA GTG GCA AGT GAT A-3' (reverse), and GAPDH, 5'-GGG GAG CCA AAA GGG TCA TC-3' (forward) and
5'-GAC GCC TGC TTC ACC ACC TTC TTG-3' (reverse). Amplification was performed under the following conditions: initial denaturation at $94^{\circ} \mathrm{C}$ for $10 \mathrm{~min}$ followed by 40 cycles of $94^{\circ} \mathrm{C}$ for $20 \mathrm{~s}$ and annealing at $53{ }^{\circ} \mathrm{C}$ for $25 \mathrm{~s}$, and a final extension at $72^{\circ} \mathrm{C}$ for $30 \mathrm{~s}$ in a Line-Gene FQD33A instrument (Bioer Inc., Hangzhou, China).

\section{Western blot analysis}

Following homogenisation of the lung tissue, the cells were subjected to lysis on incubation with $0.5 \mathrm{~mL}$ ice-cold whole-cell lysate buffer $(0.5 \mathrm{M}$ EDTA, $5 \mathrm{M} \mathrm{NaCl}, 10 \%$ Nonidet P-40, $0.1 \mathrm{M}$ phenylmethylsulphonyl fluoride, 0.1 M EGTA, 1 $M$ sodium fluoride, $1 \mathrm{M}$ HEPES, $0.2 \mathrm{M}$ sodium orthovanadate, $2 \mu \mathrm{g} / \mathrm{mL}$ aprotinin and $2 \mu \mathrm{g} / \mathrm{mL}$ leupeptin) on ice for $30 \mathrm{~min}$. Protein concentrations were determined by a Bradford assay using a kit from Bio-Rad (Bio-Rad Laboratories, Hercules, CA, USA). Equal amounts of protein $(60 \mu \mathrm{g})$ from each group were subjected to SDS-PAGE. Separated proteins were blotted and transferred to a nitrocellulose membrane and incubated with primary antibodies against p-NF-kB p65 (Ser 536), p-Ік-Ba, TNF- $\alpha$, and Foxp3 and further incubated with peroxidase-labelled secondary antibody. The immunoreactive bands were visualised with a chemiluminescence system (Amersham Bioscience, Little Chalfont, UK). The band densities of the proteins analysed were normalised to those of $\beta$-actin.

\section{Statistical analysis}

Results are presented as mean \pm standard deviation (SD), from three or six independent experiments. Data were analysed for statistical significance at $p<0.05$ by one-way analysis of variance (ANOVA) followed by Duncan's multiple range test (DMRT) as a post hoc analysis.

\section{RESULTS}

\section{Rutin reduced inflammatory cells in BALF}

Changes in total cell levels in the BALF were examined at $24 \mathrm{~h}$ after the last OVA challenge. In the OVA-sensitised mice, infiltration of inflammatory cells was observed. OVA challenge significantly $(p<0.05)$ induced influx of eosinophils and neurophils into BALF (Figure 1). Suppression of cellular infiltration was observed in OVA-challenged and rutin-administered mice. OVA-sensitised mice that were treated with rutin at $100 \mathrm{mg}$ showed reduced eosinophil and neutrophil counts versus mice treated with lower doses of rutin. The drug control Dex also exerted 
similar suppressive effects on cellular influx into BALF after OVA challenge.

\section{Rutin decreased the level of $\lg E$ in serum}

Th2-type cytokines exert important roles in the pathogenesis of allergic asthma by regulating $\lg \mathrm{E}$ production. Expression and cross-linking of allergen-specific $\lg E$ on surfaces of mast cells upon specific allergen challenge initiates early allergic asthmatic responses. Serum levels of $\lg E$ specific to OVA were measured at $24 \mathrm{~h}$ after the last OVA challenge. OVA challenge resulted in a several-fold elevation in serum OVA-specific IgE levels versus the control mice (Figure 2). Rutin administration caused a significant decrease $(p<$ 0.05 ) in the levels of OVA-specific IgE in a dosedependent manner, with the $100 \mathrm{mg}$ dose of rutin causing more marked reductions.

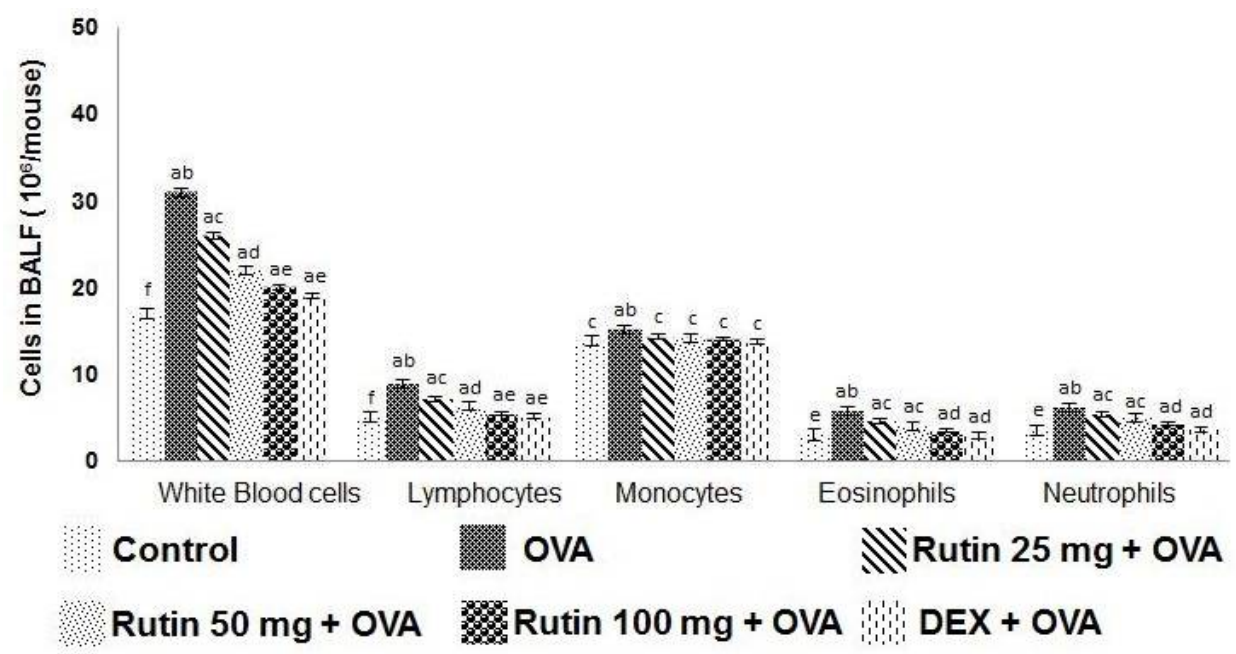

Figure 1: Effect of rutin on cell accumulation in bronchoalveolar lavage fluid (BALF). Rutin significantly reduced cellular infiltration in the BALF. Values are presented as means $\pm \mathrm{SD}, n=6$. a indicates statistical significance at $p<0.05$ vs. the respective controls; b-f indicate significant differences $(p<0.05)$ between mean values as determined by one-way analysis of variance (ANOVA) followed by Duncan's multiple range test (DMRT)

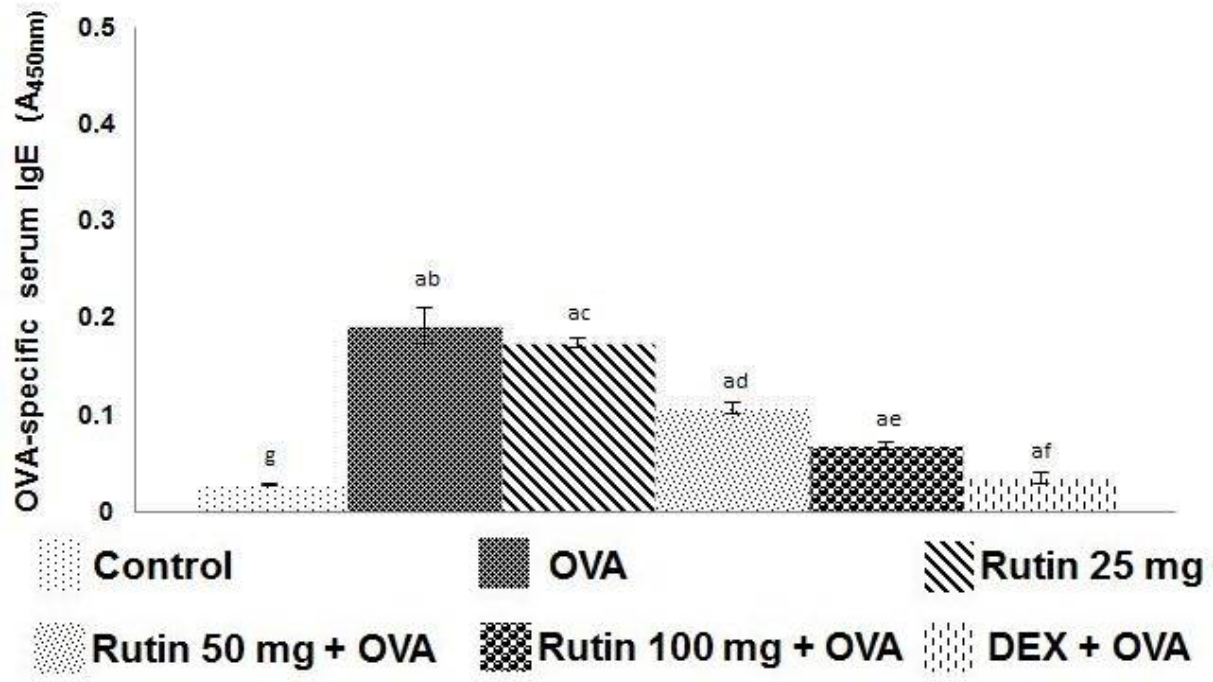

Figure 2: Rutin reduced ovalbumin (OVA)-specific lgE levels in serum. Values are presented as means $\pm \mathrm{SD}, n=$ 3. a indicates statistical significance at $p<0.05$ versus the respective controls. b-f indicate significant differences $(p<0.05)$ between mean values as determined by one-way ANOVA followed by DMRT analysis

Influence of rutin on Th2 cytokine levels and IFN-y in BALF

The influence of rutin on the expression of cytokines, (Th2 cytokines: IL-4, IL-5, and IL-13, and the Th1 cytokine, IFN- $y$ ) in BALF was determined by ELISA $24 \mathrm{~h}$ after final OVA challenge. OVA challenge caused significantly increased $(p<0.05)$ BALF levels of IL-4, IL-5, and IL-13 versus the control group (Figure 3). However, the level of IFN-y was slightly lower than the control group level. Rutin administration 


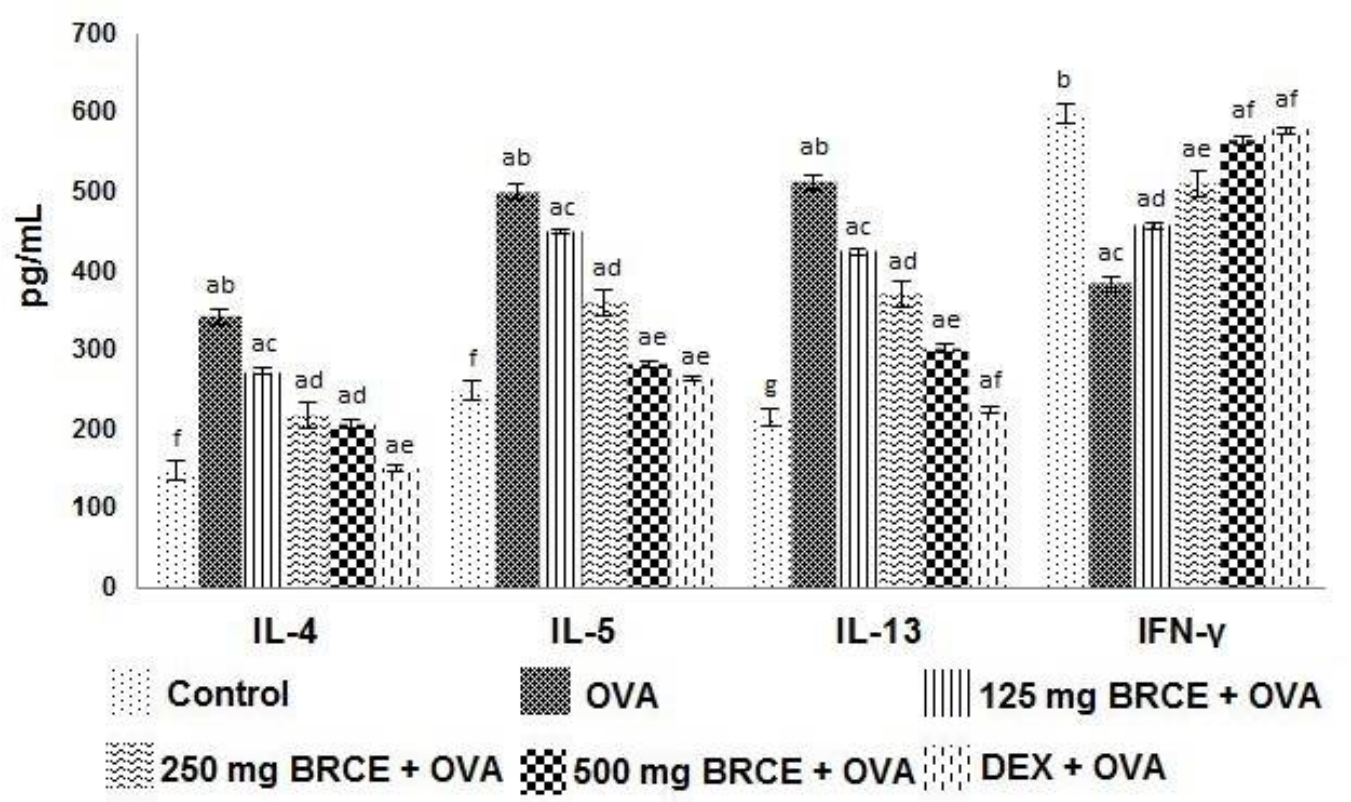

Figure 3. Effects of rutin on the levels of Th2 cytokines and IFN- $y$ in BALF. Values are presented as means \pm $\mathrm{SD}, n=3$; a indicates statistical significance at $p<0.05$ versus the respective controls. b-f represent significant differences $(p<0.05)$ between mean values within the groups of the same cell line, as determined by one-way ANOVA followed by DMRT analysis

caused a marked decrease in the level of Th2 cytokines, in a dose-dependent manner, with a gradual increase in the level of IFN-y in BALF. Rutin at $25 \mathrm{mg}$ caused a reduction in levels of IL4, IL-5, and IL-13; the higher doses of 50 and $100 \mathrm{mg}$ caused more pronounced decreases with a significant increase in BALF IFN-y levels.

\section{Rutin improved airway function and reduced airway hyperresponsiveness}

The effect of rutin on $\mathrm{AHR}$ in response to increasing concentrations of methacholine was determined. AHR is the excessive narrowing of the airways in response to various allergic stimuli as contractile agonists of OVA. Asthma is characterised by AHR. RI and Cdyn were measured following OVA challenge. Cdyn refers to lung distensibility and is defined as the change in volume of the lung produced by pressure change across the lung. RI can be defined as the pressure driving respiration divided by the air flow. In our study, the OVA-challenged mice developed high $A H R$, indicated by high $R I$ and low Cdyn (Figure 4a, b). Treatment with rutin (25, 50 , or $100 \mathrm{mg})$ markedly $(p<0.05)$ restored Cdyn and reduced $\mathrm{RI}$ in OVA-challenged mice in response to methacholine in a dose-dependent manner.

\section{Rutin restored lung architecture}

Histological analysis was conducted to assess changes in the architecture of the lung tissue. $\mathrm{H} \& \mathrm{E}$ analysis showed that OVA challenge induced marked infiltration of inflammatory cells into the peribronchiolar and perivascular connective tissues versus normal lung tissue (Figure 5). Rutin (25, 50 or $100 \mathrm{mg} / \mathrm{kg}$ ) strikingly suppressed infiltration of eosinophils and neutrophils in the lung tissues and also restored the normal histology. Dexamethasone treatment also resulted in tissue sections with almost negligible alterations and infiltration versus the control. Rutin at $100 \mathrm{mg}$ showed almost no change in the extent of inflammatory cell infiltration, similar to normal histology. Furthermore, goblet cell hyperplasia with hypersecretion of mucus was observed in OVAchallenged mice, and was almost normalised upon rutin treatment (Figure 6).

\section{Rutin modulated expression levels of proteins in the inflammatory pathway}

The pathogenesis of asthma development is associated with NF-KB activation. OVA challenge resulted in a robust increase in the expression levels of $\mathrm{p}-\mathrm{NF}-\mathrm{kB}$ p65 (Ser 536), p-I-KBa, and TNF- $\alpha$, whereas Foxp3 expression was downregulated (Figure 7). However rutin administration caused significant decreases in the levels of NF-kB p65, p-I-kBa, and TNF- $\alpha$, with $s$ substantially elevated level of Foxp3. Furthermore, to assess the effects of rutin on Foxp3 expression at the mRNA level, RT-PCR was performed. Rutin at 25, 50, and $100 \mathrm{mg}$ upregulated Foxp3 mRNA in a dose-dependent manner (Figure 7). The anti-inflammatory effects of rutin could also be due in part to the increased 



Figure 4: Effect of rutin on airway hyperresponsiveness. Rutin markedly reduced airway resistance and improved lung compliance in mice exposed to OVA. Values are presented as means $\pm S D ; n=6$

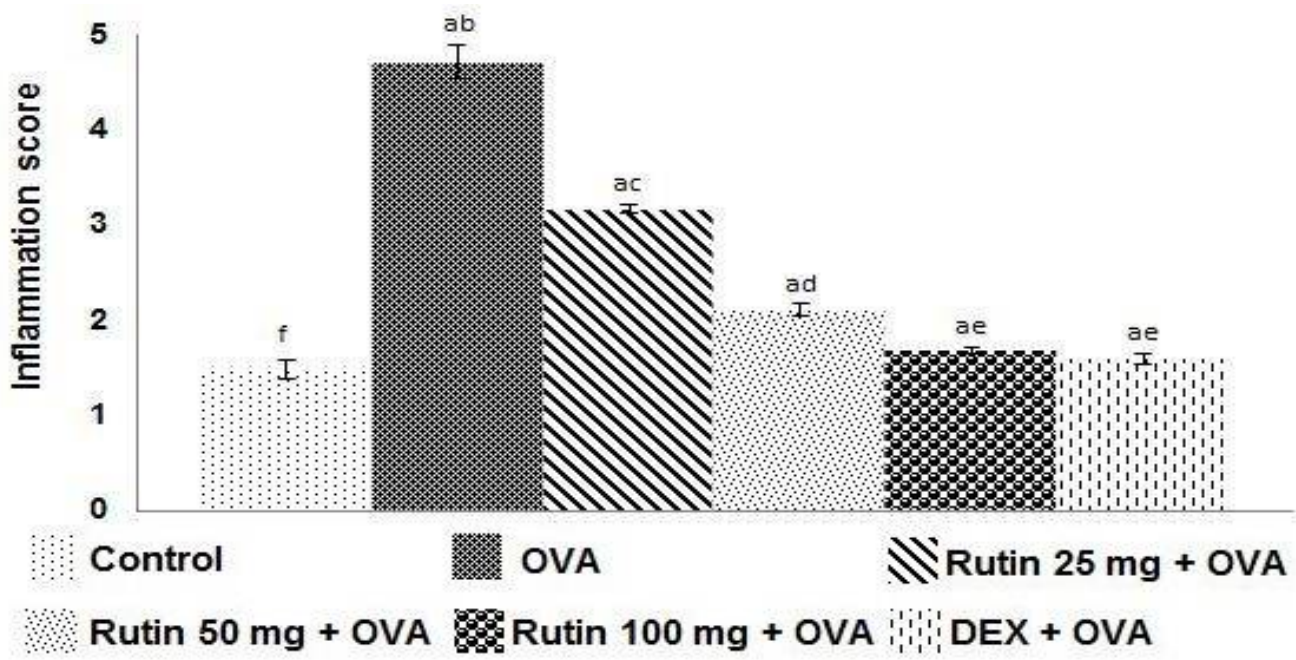

Figure 5: Rutin reduced inflammatory cell infiltration. Rutin markedly inhibited inflammatory cell recruitment into lung tissue. Values are presented as means $\pm \mathrm{SD}, n=3$; a indicates statistical significance at $p<0.05$ versus the respective controls; $b-f$ represent significant differences $(p<0.05)$ between mean values, as determined by oneway ANOVA followed by DMRT analysis 


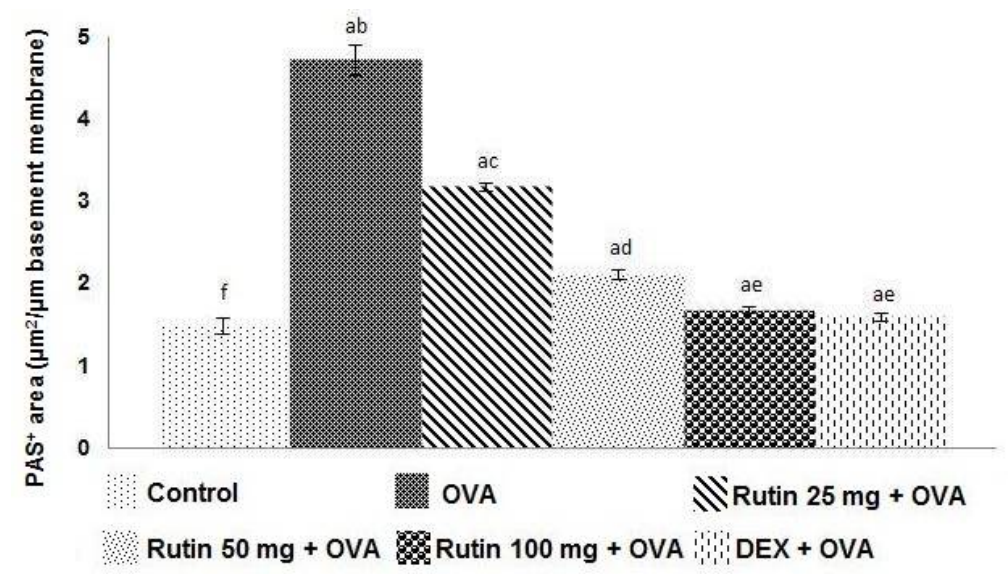

Figure 6: Rutin reduced mucus hypersecretion. Mucus hypersecretion is a characteristic of allergic asthma. Rutin markedly reduced mucus accumulation and hypersecretion in the bronchioles. Values are presented as means \pm $\mathrm{SD}, n=3$. a indicates statistical significance at $p<0.05$ versus the respective controls; $\mathrm{b}-\mathrm{f}$ indicate significant differences $(p<0.05)$ between mean values, as determined by one-way ANOVA followed by DMRT analysis

a

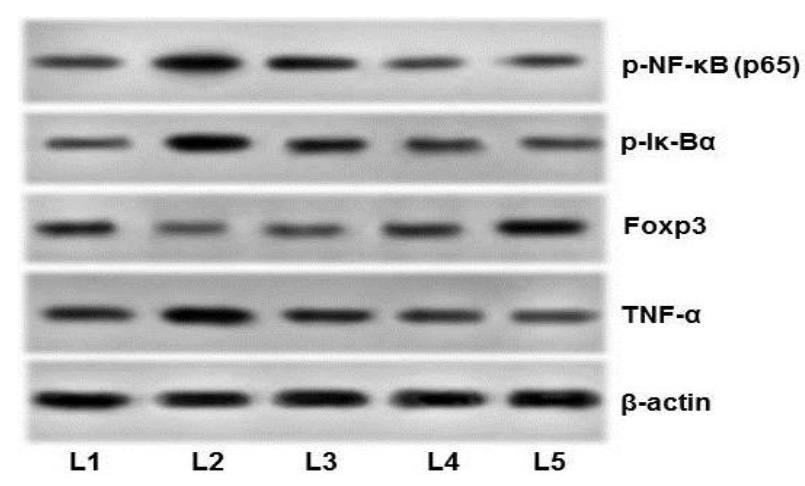

b

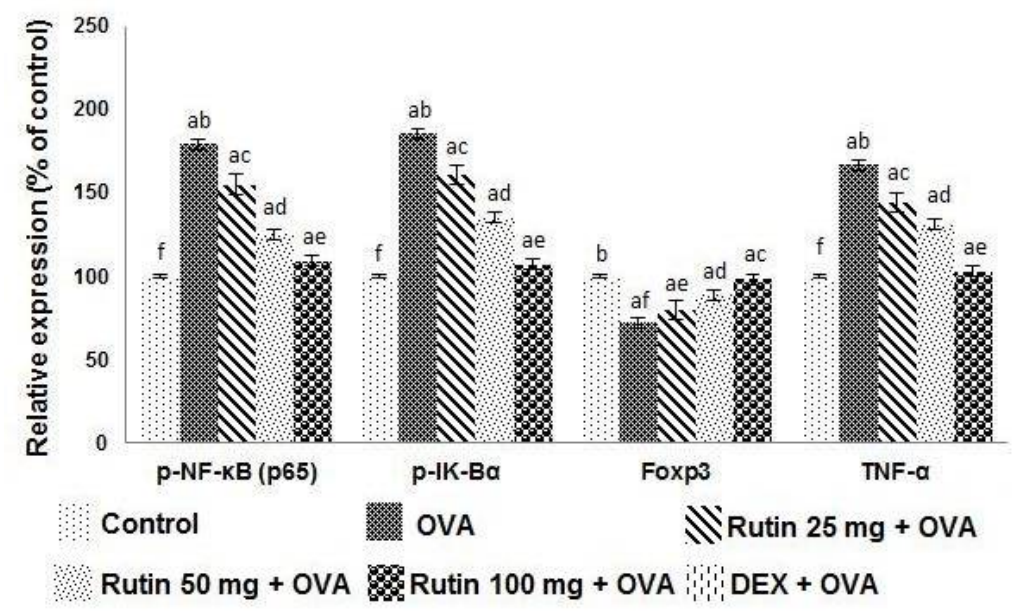

C

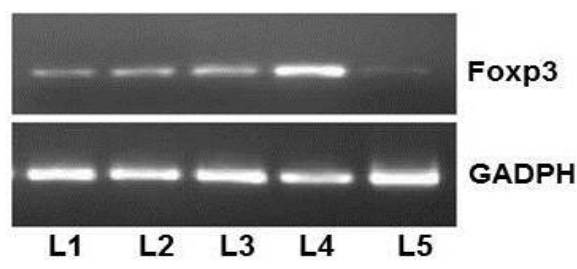

Figure 7: Effects of rutin on the levels of inflammatory mediators and Foxp3. OVA-induced enhanced expression of NF-kB signalling pathway proteins and decreased Foxp3 expression were modulated effectively by rutin. Values are presented as means $\pm \mathrm{SD}, n=3$; a indicates statistical significance at $p<0.05$ versus the respective controls; b-f represent significant differences $(p<0.05)$ between mean values. as determined by one-way ANOVA followed by DMRT analysis; (L1-Control; L2-OVA; L3-25 mg Rutin + OVA; L4-50 mg Rutin + OVA; L5100 mg Rutin + OVA) 


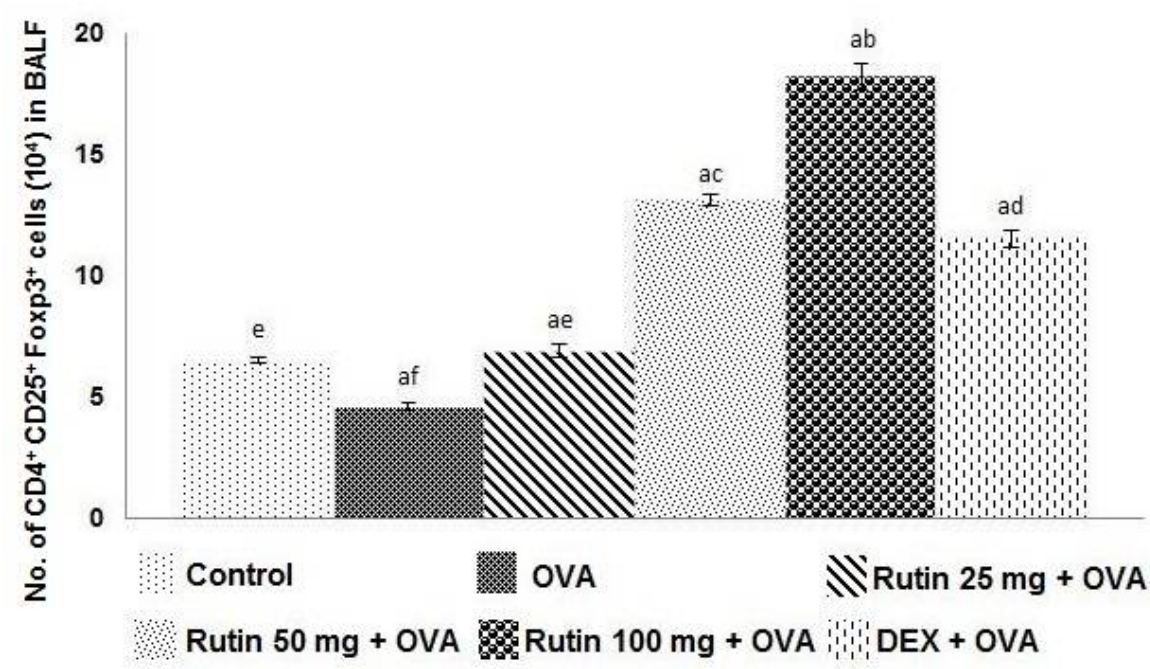

Figure 8. Rutin increased the CD4 ${ }^{+} \mathrm{CD}_{2} 5^{+}$Foxp3 $3^{+}$Treg population in BALF. CD4 ${ }^{+}$CD25 $5^{+}$Foxp3 ${ }^{+}$Tregs are key in maintaining immune homeostasis. Rutin markedly increased the $\mathrm{CD} 4^{+} \mathrm{CD} 25^{+} \mathrm{Foxp}^{+} \mathrm{Treg}$ cell population. Values are presented as means $\pm \mathrm{SD}, n=3$. a indicates statistical significance at $p<0.05$ versus the respective controls. $b-f$ represent significant differences $(p<0.05)$ between mean values within groups of the same cell line, as determined by one-way ANOVA followed by DMRT analysis

expression of Foxp3. These results suggest antiinflammatory effects of rutin.

\section{Influence of rutin on the $\mathrm{CD}^{+} \mathrm{CD}^{+} 5^{+} \mathrm{Foxp}^{+}$ Treg population in BALF}

$\mathrm{CD}^{+} \mathrm{CD}^{2} 5^{+}$Foxp3 $^{+}$Treg cells play an important role in the regulation of asthma pathogenesis. Furthermore, allergen-specific Tregs are key in asthma therapy. In our study, we examined the population of $\mathrm{CD}^{+} \mathrm{CD}^{+} 5^{+} \mathrm{Foxp}^{+}$Tregs in BALF of OVA-challenged mice. OVA challenge significantly reduced the $\mathrm{CD}^{+} \mathrm{CD}^{+} 5^{+} \mathrm{Foxp}^{+}$ Treg cell population (Figure 8). However, rutin administration caused a striking increase in the level of $\mathrm{CD}^{+} \mathrm{CD}^{+} 5^{+} \mathrm{Foxp}^{+}$Tregs that was consistent with Foxp3 mRNA expression. The $100 \mathrm{mg}$ dose of rutin resulted in an increased population of these cells, suggesting an effect of rutin against OVA-induced allergic asthma.

\section{DISCUSSION}

Asthma is a chronic inflammatory disease of the lungs, characterised by infiltration of inflammatory cells, especially eosinophils, into the lungs and airways, leading to AHR, bronchoconstriction, and mucus production [14]. The prevalence of asthma is increasing rapidly worldwide; the disease may cause severe morbidity and even mortality in aggravated episodes. Currently, inhaled corticosteroids (ICSs) and bronchodilators are employed for asthma management for relieving bronchoconstriction [18]. Nevertheless, prolonged use of ICS at higher doses, in particular, has been reported to be associated with side effects [18] and oesophageal candidiasis [19]. Thus, there is a continuing need for the identification of new and targeted approaches. In our study, we investigated the role of rutin in exerting protective effects in an OVA-induced asthma model.

In asthma, bronchoconstriction occurs due to contraction or hypertrophy of airway smooth muscles and inflammation, leading to decreased lung function [20]. AHR is a measure of such bronchial constriction. OVA-induced mice showed severely impaired Cdyn and increased AR. However, rutin reduced AR and improved lung function in response to inhaled methacholine.

Migration of inflammatory cells, specifically eosinophils and lymphocytes, into the lungs is a key event in allergic asthma and is a major cause of allergic airway inflammation [21]. An increase in the number of eosinophils and neutrophils in BALF is a characteristic of asthma. In the present study, rutin significantly reduced the infiltration of inflammatory cells in BALF and lung tissues.

The marked increase in levels of cytokines (IL-4, IL-5, IL-13) in BALF observed in our study following OVA sensitisation and challenge, along with the increased recruitment of inflammatory cells, is suggestive of AHR. In allergic asthma, the Th2 cytokines have been found to play vital roles in the pathogenesis of inflammation and also induce many features of asthma [22]. Effective decreases in the levels of Th2 cytokines with a substantial increase in IFN- $\gamma$ levels showed the efficacy of rutin in inhibiting OVAinduced airway inflammation and enhancing Th2 
responses. Additionally, the balance of Th1/Th2 cytokines is essential in regulating inflammatory responses. It is known that asthma and inflammatory responses are associated with the increased production of Th2 cytokines (IL-4, IL-5, IL-13) and reduced levels of the Th1 cytokine IFN-y. Here, rutin reduced Th2 cytokine levels while improving IFN-y levels, indicating a positive Th1/Th2 cytokine balance and anti-inflammatory effects. These observed decreases in Th2 cytokines could also have caused decreased inflammatory cell recruitment in BALF. Because $\mathrm{IL}-4, \quad \mathrm{IL}-5$, and IL-13 are associated with activation of eosinophils and production of IgE by $B$ cells, the decrease in cytokine levels by rutin could have also contributed to the decreased $\lg \mathrm{E}$ levels in serum, which could also have been due to the suppression of $\lg E$ production by rutin itself.

Consistent with the BALF levels of cytokines and cellular infiltration, the histopathological analysis with H\&E and PAS staining revealed increased infiltration of inflammatory cells, and the characteristic morphology of cells, with hyperproduction of mucus by goblet cells upon OVA challenge. Activation of allergen-induced Th2 cells has been reported to be associated with goblet cell hyperplasia and increased mucus secretion [23]. Rutin treatment caused the suppression of PAS-positive cell counts and area in bronchial tissues of OVA-challenged mice. Hypersecretion of mucus in the airway, along with allergic inflammation, plays a major role in the pathogenesis of asthma. Mucus accumulation in the bronchus narrows the airway and increases AHR. Rutin-induced inhibition of inflammatory cell infiltration, in BALF and in lung tissues, along with the decrease in cytokine secretion could also have contributed to decreased mucus production.

Moreover, continued activation of NF-KB has been observed in allergic airway inflammation and is believed to be involved in airway remodelling in human and animal models of asthma [24]. NF-KB, as a vital transcription factor in Th2 cell differentiation [25], regulates innate and adaptive immune responses by causing the expression of various genes that are involved in inflammation, as well as leukocyte migration and activation. Nevertheless, in cells not stimulated by allergens, NF-KB remains sequestered in the cytoplasm by an inhibitor of $\mathrm{KB}$ (IKB) [26], whereas upon activation, NF-KB unit p65 translocates from the cytoplasm to the nucleus, eventually leading to the synthesis and subsequent release of proinflammatory cytokines [27]. The increased expression of NF-KB p65, pIKB, and TNF- $\alpha$ suggests the activation of NF-KB in OVA-challenged mice, thus leading to expression of cytokines and inflammatory mediators. Rutin was found to also suppress the activation of NF-kB p65, IkB, and TNF- $\alpha$, thus suppressing the NF-KB signalling pathway leading to inflammatory responses.

Tregs, a specialised sub-population of $\mathrm{T}$ cells, exert important roles in autoimmunity and immune tolerance. A considerable amount of research has focused on naturally occurring $\mathrm{CD}^{+} \mathrm{CD} 25^{+}$Tregs that have been shown to be critically involved in preventing autoimmunity [28]. $\mathrm{CD}^{+} \mathrm{CD}^{+} 5^{+}$Tregs that co-express forkhead/winged helix transcription factor (Foxp3) exhibit strong anti-inflammatory roles and function to maintain tolerance to selfcomponents, either through direct contact with cells or by releasing anti-inflammatory cytokines such as IL-10 [29]. Rutin at the doses tested was found to markedly enhance the percentage of $\mathrm{CD}^{+} \mathrm{CD}^{2} 5^{+} \mathrm{Foxp}^{+}$Tregs in BALF versus the OVA control, with the $100 \mathrm{mg}$ dose showing the maximum effect. Moreover, rutin treatment also upregulated the expression of Foxp3.

The observed reductions in airway inflammation upon rutin treatment could be due, in part, to the inhibitory effects on IL-4, IL-5, and IL-13, and also to enhanced numbers of $\mathrm{CD}^{+} \mathrm{CD}^{+} 5^{+}$ Foxp3 $^{+}$Tregs. Foxp3 functions as a transcriptional repressor for various transcription factors, such as nuclear factor of activated $T$ cells (NFAT), NF-kB, and Runx1 [30], thus suggesting possible multi-target molecular effects of rutin. Furthermore, Foxp ${ }^{+}$Tregs are known to inhibit eosinophil recruitment, mucus hyper-production, and Th2 cytokine release [29]. Thus, the enhanced Foxp3 expression and increased $\mathrm{CD}^{+} \mathrm{CD}^{+} 5^{+} \mathrm{Foxp}^{+}$Tregs on rutin treatment indicate potent anti-inflammatory effects of rutin in OVA-challenged mice.

\section{CONCLUSION}

Rutin effectively suppressed the expression of inflammatory mediators and regulated NF-KB signalling, indicating the effectiveness of rutin as a potential candidate for the treatment of allergic asthma. More clinical research is needed to further explore the molecular events involved.

\section{DECLARATIONS}

\section{Acknowledgement}

The authors acknowledge that this study was supported by Second Hospital Affiliated to Zhejiang University School of Medicine. 


\section{Conflict of Interest}

No conflict of interest associated with this work.

\section{Contribution of Authors}

The authors declare that this work was done by the authors named in this article and all liabilities pertaining to claims relating to the content of this article will be borne by them.

\section{Open Access}

This is an Open Access article that uses a funding model which does not charge readers or their institutions for access and distributed under the terms of the Creative Commons Attribution License (http://creativecommons.org/licenses/by/ 4.0) and the Budapest Open Access Initiative (http://www.budapestopenaccessinitiative.org/rea d), which permit unrestricted use, distribution, and reproduction in any medium, provided the original work is properly credited.

\section{REFERENCES}

1. Galli SJ, Tsai M, Piliponsky AM. The development of allergic inflammation. Nature 2008; 454: 445-454.

2. Braman SS. The global burden of asthma. Chest 2006; 130: $4 S-12 S$.

3. Elias JA, Lee CG, Zheng T, Ma B, Homer RJ, Zhu Z. New insights into the pathogenesis of asthma. $J$ Clin Invest 2003; 111: 291-297.

4. Kips JC, Tournoy KG, Pauwels RA. New anti-asthma therapies: suppression of the effect of interleukin (IL)-4 and IL-5. Eur Respir J 2001; 17: 499-506.

5. Gagliardo R, Chanez P, Mathieu M, Bruno A, Costanzo $G$, Gougat C, Vachier I, Bousquet J, Bonisignore G, Vignola AM. Persistent activation of nuclear factor-kB signaling pathway in severe uncontrolled asthma. $A m \mathrm{~J}$ Respir Crit Care Med 2003; 168: 1190-1198.

6. Choi IW, Kim DK, Ko HM, Lee HK. Administration of antisense phosphorothioate oligonucleotide to the p65 subunit of NF-kappaB inhibits established asthmatic reaction in mice. Int Immunopharmacol 2004; 4: 18171828.

7. Tritar-Cherif F, BenM'Rad S, Merai S, Djenayah F. Corticotherapy for asthma in the child. LaTunisieMédicale 2002; 80: 1-6.

8. Shahzad M, Yang $X$, Raza Asim $M B$, Sun $Q$, Han $Y$, Zhang $F$, Cao $Y$, Lu S. Black seed oil ameliorates allergic airway inflammation by inhibiting $T$-cell proliferation in rats. Pulmonary Pharmacology and Therapeutics 2009; 22: 37-43.

9. Wen MC, Wei CH, Hu ZQ, Srivastava K, Ko J, Xi ST, Mu $D Z, D u J B, L i G H$, Wallenstein S, et al. Efficacy and tolerability of anti-asthma herbal medicine intervention in adult patients with moderate-severe allergic asthma. $J$ Allergy Clinical Immunol 2005; 116: 517-524.

10. Rogers J, Perkins I, van Olphen A, Burdash N, Klein TW, Friedman $H$. Epigallocatechin gallate modulates cytokine production by bone marrow-derived dendritic cells stimulated with lipopolysaccharide or muramyldipeptide, or infected with Legionella pneumophila. Exp Biol Med (Maywood) 2005; 230 : 645651.

11. Guardia T, Rotelli AE, Juarez AO, Pelzer LE. Antiinflammatory properties of plant flavonoids. Effects of rutin, quercetin and hesperidin on adjuvant arthritis in rat. Farmaco 2001; 56: 683-687.

12. Garber JC. (Chair) Committee for the Update of the Guide for the Care and Use of Laboratory Animals. Guide for the Care and Use of Laboratory Animals, 8 edition. National Academy of Sciences. 2011.

13. Oh SW, Pae Cl, Lee DK, Jones F, Chiang GK, Kim HO, Moon SH, Cao B, Ogbu C, Jeong KW, et al. Tryptase inhibition blocks airway inflammation in a mouse asthma model. J Immunol 2002; 168: 1992-2000.

14. Djukanovic R, Roche WR, Wilson JW, Beasley CR, Twentyman OP, Howarth RH, Holgate ST. Mucosal inflammation in asthma. Am Rev Respir Dis 1990; 142: 434-457.

15. Pichavant M, Goya S, Hamelmann E, Gelfand EW, Umetsu DT. Animal models of airway sensitization. Curr Protoc Immunol 2007: 15.18.1-15.18.19.

16. Bao Z, Guan SP, Cheng C, Wu S, Wong SH, Kemeny $D M$, Leung BP, Wong WSF. A novel antiinflammatory role for andrographolide in asthma via inhibition of the NF-KB pathway. Am J Respir Crit Care Med 2009; 179: 657-665.

17. Jin $H$, Luo $Q$, Zheng $Y$, Nurahmat $M, W u J, L i B, L v Y$, Wang G, Duan X, Dong J. CD4+CD25+Foxp3+ $T$ cells contribute to the antiasthmatic effects of Astragalus membranaceus. Int Immunopharmacol 2013; 15: 42-49.

18. Li XM. Complementary and alternative medicine in pediatric allergic disorders. Curr Opin Allergy Clin Immunol 2009; 9: 161-167.

19. Fukushima C, Matsuse H, Tomari S, Obase Y, Miyazaki $Y$, Shimoda T, Kohno S. Oral candidiasis associated with inhaled corticosteroid use: comparison of fluticasone and beclomethasone. Ann Allergy Asthma Immunol 2003; 90: 646-651.

20. Wenzel SE. Asthma: defining of the persistent adult phenotypes. Lancet 2006; 368: 804-813.

21. Elsner J, Kapp A. Regulation and modulation of eosinophil effector functions. Allergy 1999; 54: 15-26.

22. Lloyd CM, Hessel EM. Functions of $T$ cells in asthma: more than just $T(H) 2$ cells. Nat Rev Immunol 2010; 10 : 838-848.

23. Morcillo EJ, Cortijo J. Mucus and MUC in asthma. Curr Opin Pulm Med 2006; 12: 1-6.

24. Smith DE. IL-33: a tissue derived cytokine pathway involved in allergic inflammation and asthma. Clin Exp Allergy 2010; 40: 200-208. 
25. Siebenlist U, Brown K, Claudio E. Control of lymphocyte development by NFkB. Nat Rev Immunol 2005; 5:435445.

26. Juneja L, Parmar HS. Ovalbumin induced allergic rhinitis and development of prediabetes to rats: possible role of Th2 cytokines. Inflamm Allergy Drug Targets 2013; 12: 199-205.

27. Boulanger D, Bureau F, Melotte D, Mainil J, Lekeux P. Increased nuclear factor kappaB activity in milk cells of mastitis-affected cows. J Dairy Sci 2003; 86:1259-1267.

28. MacConmara MP, Maung AA, Fujimi S. Increased $C D 4+C D 25+T$ regulatory cell activity in trauma patients depresses protective Th1 immunity. Ann Surg 2006; 244: 514-523.

29. Ma C, Ma Z, Liao XL, Liu J, Fu Q, Ma S. Immunoregulatory effects of glycyrrhizic acid exerts antiasthmatic effects via modulation of Th1/Th2 cytokines and enhancement of CD4(+)CD25(+)Foxp3+ regulatory $T$ cells in ovalbumin-sensitized mice. J Ethnopharmacol 2013; 148: 755-762.

30. Bettelli E, Dastrange M, Oukka M. Foxp3 interacts with nuclear factor of activated $T$ cells and NF-kappa $B$ to repress cytokine gene expression and effector functions of $T$ helper cells. Proc Natl Acad Sci USA 2005; 102: 5138-5143. 